\title{
Simple Method of Tocopherol Determination in Plasma Lipoprotein Fractions Using a Heparin-Ca Precipitation Technique
}

\author{
Makoto Kitagawa, * Toshie MoritA, and Makoto MINO ${ }^{1}$ \\ Department of Pediatrics, Osaka Medical College, Takatsuki 569, Japan
}

(Received March 13, 1989)

\begin{abstract}
Summary A simple and convenient method using a heparin-Ca precipitation technique, which was devised for determination of serum lipoprotein fractions, was applied to the determination of tocopherol concentrations in individual lipoproteins. Three types of precipitates were prepared from $0.25 \mathrm{ml}$ serum samples plus $0.1 \mathrm{ml}$ of $5 \%$ heparin by mixing at $37^{\circ} \mathrm{C}$ for $30 \mathrm{~min}$ with $5 \mathrm{ml}$ of $0.054 \mathrm{M} \mathrm{CaCl}_{2}$ only, $0.054 \mathrm{M} \mathrm{CaCl}_{2}$ in $0.6 \%$ $\mathrm{NaCl}$, or $0.054 \mathrm{M} \mathrm{CaCl}_{2}$ in $0.92 \% \mathrm{NaCl}$. These three precipitates consisted of chylomicron + VLDL (very low-density lipoprotein) + LDL (low density lipoprotein), chylomicron + VLDL, and chylomicron only, respectively. The tocopherol content of individual lipoproteins was calculated from the concentrations of tocopherol in these three precipitates, and the values obtained by using this technique were very close to those by a standard ultracentrifugation method. Thus, this simple method appears to be suitable for rapid tocopherol assay of a large number of samples.
\end{abstract}

Key Words vitamin E, lipoproteins, serum, precipitation technique

In view of the delivery of tocopherol to effective sites in tissues and cells, circulating tocopherol is believed to be distributed into lipoproteins since there are no specific carrier proteins for circulating tocopherol. Therefore, it may be important to investigate tocopherol distribution between individual lipoproteins in order to assess nutritional status and investigate the transfer mechanism of vitamin E.

Various techniques have been used for separation of lipoprotein fractions, e.g., centrifugation, electrophoresis, and gel filtration; among them, an ultracentrifugation technique has been generally employed as a standard method(1). However, this method is not suitable for clinical population studies due to the necessity for simultaneous preparation of many samples, in addition to excessive time consumption and the large amount of blood necessary for tocopherol assay of the individual lipoprotein fractions. Therefore, the previous reports regarding

${ }^{1}$ 北川 真, 森田利江, 美濃 真

* To whom correspondence should be addressed. 
tocopherol distribution among lipoproteins in human (2-7) have been limited to studies with small groups of adult cases.

Accordingly, the authors have attempted to determine tocopherol content of lipoprotein fractions by the heparin-Ca precipitation technique $(8-10)$, which is routinely used for HDL (high-density lipoprotein)-cholesterol determination in clinical laboratories.

\section{MATERIALS AND METHODS}

Principle. Lipoproteins in serum are known to be precipitated by polyanions and divalent cations, due to formation of insoluble complexes. The formation of precipitate by the individual lipoprotein groups varies according to the ion strength of the solution. Sasaki et al.(10) reported that when heparin and calcium were added to serum together with various concentrations of sodium chloride to change ion strength, the precipitates formed with individual lipoproteins could be divided into three groups, i.e., LDL (low density lipoprotein) + VLDL (very low-density lipoprotein) + chylomicron, VLDL + chylomicron, and chylomicron. The individual lipoproteins can then be calculated by nephelometrically measuring the turbidity of these three types of precipitates. By assaying tocopherol in the three types of precipitates, the tocopherol concentrations of each lipoprotein fraction can be determined by a similar calculation.

Reagents for precipitation of lipoproteins:

1) Solution A: $0.054 \mathrm{M} \mathrm{CaCl}_{2}$ in $0.92 \% \mathrm{NaCl}$

2) Solution B: $0.054 \mathrm{M} \mathrm{CaCl}_{2}$ in $0.6 \% \mathrm{NaCl}$

3) Solution $\mathrm{C}: 0.054 \mathrm{M} \mathrm{CaCl}_{2}$ in distilled water

4) $5 \%$ heparin solution is prepared from commercial heparin (Heparin-Na, Wako Chemicals Co., Tokyo).

Procedures. A $0.25 \mathrm{ml}$ serum sample with a $0.1 \mathrm{ml}$ aliquot of $5 \%$ heparin was placed into each of three tubes, and then $5 \mathrm{ml}$ of the solutions $\mathrm{A}, \mathrm{B}$, or C was added. After incubation at $37^{\circ} \mathrm{C}$ for $30 \mathrm{~min}$ while stirring with a magnet stirrer, the precipitates produced in each tube were filtered and absorbed onto a $0.45 \mu \mathrm{M}$ membrane filter, and then the membranes with adhering precipitates were provided for tocopherol assay together with $0.5 \mathrm{ml}$ of $n$-saline. Tocopherol concentration of the whole serum was also assayed, concurrently. All blood samples were obtained from healthy adult volunteers in our laboratory and the ethics committee at the hospital approved the study protocol.

As shown in Fig. 1, precipitates from the tubes with solutions A, B, and C were composed of chylomicron, chylomicron + VLDL, and chylomicron + VLDL+ LDL, respectively. Thus, the tocopherol concentration in chylomicron was determined in the precipitate with solution $\mathrm{A}$, while tocopherol concentrations in the other lipoprotein fractions were calculated from the three types of precipitates and the total serum tocopherol value, i.e., the tocopherol content in VLDL was B minus $\mathrm{A}$, that in LDL was $\mathrm{C}$ minus $\mathrm{B}$, and that in HDL was total serum toco- 


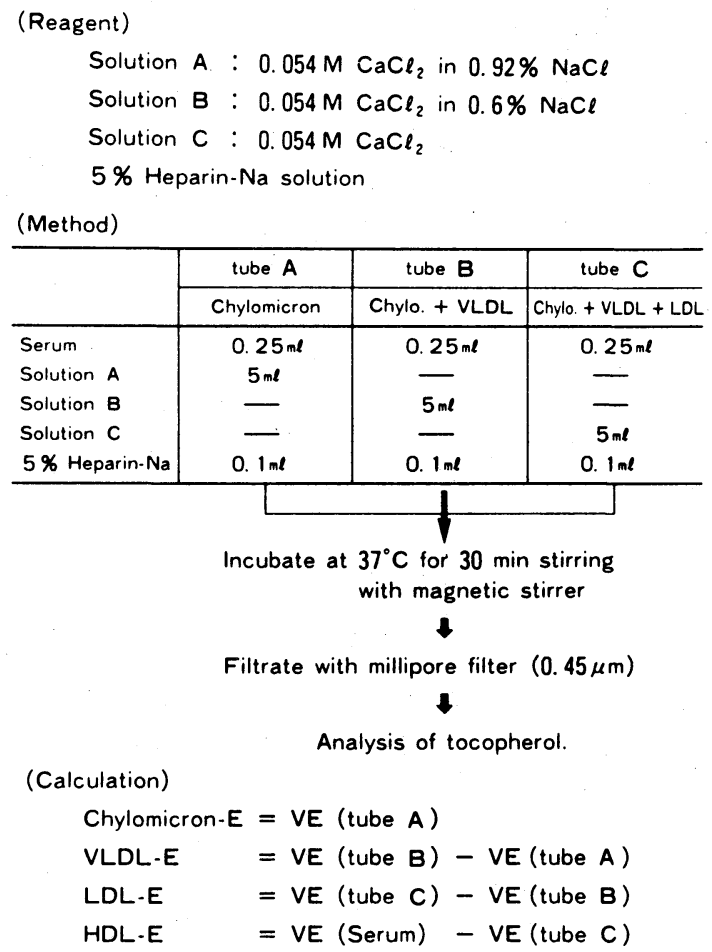

Fig. 1. Procedure for tocopherol determination in plasma lipoprotein fraction using heparin-Ca precipitation technique.

pherol minus $\mathrm{C}$.

Tocopherol assay was performed by saponification as described in previous repots (11).

The sum of the quantities of tocopherol recovered in the three precipitates and the filtrates came to more than $95 \%$ of the tocopherol content of whole serum.

Lipoproteins were separated by ultracentrifugation as follows. After the serum was separated from the blood, serum lipoproteins were fractionated by flotation ultracentrifugation according to the method of Hatch and Lees (1), within $6 \mathrm{~h}$ after isolation of the serum. The serum subsequently was centrifuged with densities adjusted by $\mathrm{NaBr}$ at $4^{\circ} \mathrm{C}$ using a Hitachi $65 \mathrm{P}-7$ ultracentrifuge with a type RP-65 rotor (Hitachi Koki Co., Ltd.). Tocopherol was also assayed in the individual lipoprotein fraction.

\section{RESULTS AND DISCUSSION}

1. Relationship between heparin concentration, reaction temperature, and precipitate formation

Figure 2 shows the relation of $\mathrm{NaCl}$ concentration to precipitate formation, Vol. 35, No. 4, 1989 


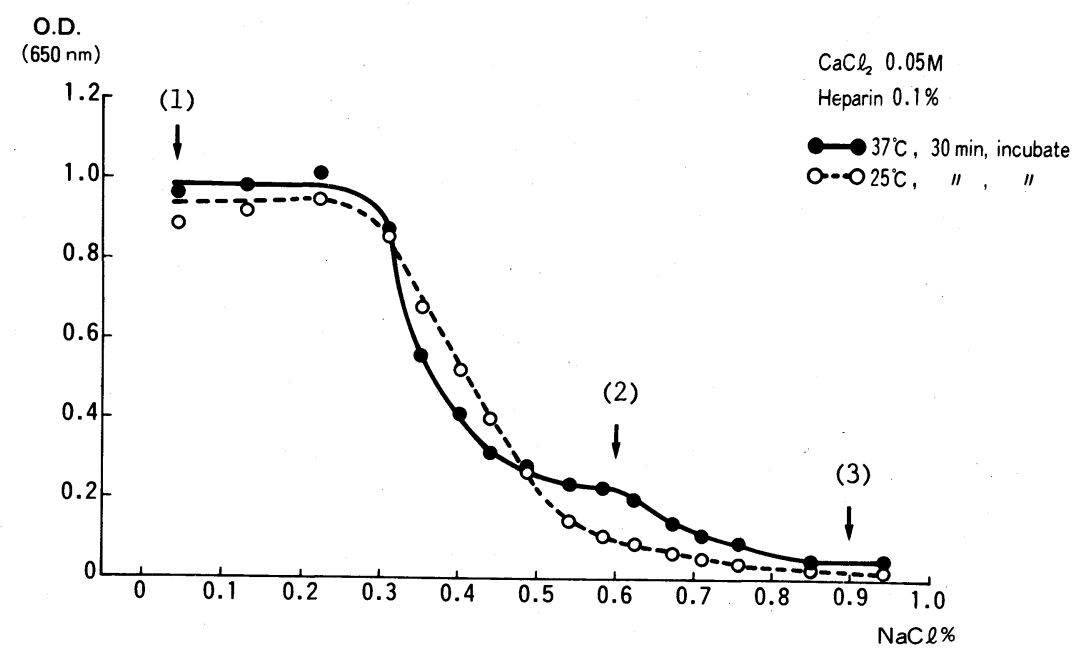

Fig. 2. Variation of precipitate formation with $\mathrm{NaCl}$ concentration at $25^{\circ} \mathrm{C}(\mathrm{O})$ and at $37^{\circ} \mathrm{C}(\bullet) . \mathrm{CaCl}_{2}$ and heparin concentrations were fixed at $0.05 \mathrm{M}$ and $0.1 \%$. (1) Chylomicron + VLDL + LDL, (2) chylomicron + VLDL, and (3) chylomicron were precipitated in $0,0.60$, and $0.9 \% \mathrm{NaCl}$ concentrations, respectively.

with $\mathrm{CaCl}_{2}$ and heparin concentrations fixed at $0.05 \mathrm{M}$ and $0.1 \%$, respectively. The chylomicron + VLDL + LDL, as well as chylomicron fractions were precipitated uniformly over a relatively wide range of $\mathrm{NaCl}$ concentrations at both temperatures, while the precipitated fraction corresponding to chylomicron + VLDL varied continuously with changes in $\mathrm{NaCl}$ concentrations at $25^{\circ} \mathrm{C}$. However, in the reaction at $37^{\circ} \mathrm{C}$, precipitate formation was almost constant for $\mathrm{NaCl}$ concentrations between 0.5 and $0.6 \%$. Therefore, a reaction temperature of $37^{\circ} \mathrm{C}$ is required to obtain constant precipitate formation corresponding to the latter type of lipoproteins.

Figure 3 shows the dependence of precipitate formation upon heparin concentration, temperature, and $\mathrm{NaCl}$ concentration. $\mathrm{CaCl}_{2}$ concentration and reaction time were fixed at $0.05 \mathrm{M}$ and $30 \mathrm{~min}$, respectively. A constant precipitate was obtained at concentrations of heparin exceeding $0.05 \%$ for every $\mathrm{NaCl}$ concentration from 0 to $0.9 \%$. This indicates that a heparin concentration above $0.05 \%$ is required to obtain quantitatively constant precipitation.

With regard to the reaction temperature, the precipitate formation differed considerably between $25^{\circ} \mathrm{C}$ and $37^{\circ} \mathrm{C}$ in the case of solution $\mathrm{B}$, in which chylomicron + VLDL is precipitated, while there were no differences in precipitate formation between these two temperatures for solutions $\mathrm{A}$ and $\mathrm{C}$. At $25^{\circ} \mathrm{C}$, an unsuitable type of precipitation developed, in which isolation of the lipoprotein fractions was found to be inadequate on the basis of electrophoretical confirmation as described later.

On the basis of the above results, the reaction conditions were fixed as follows: 


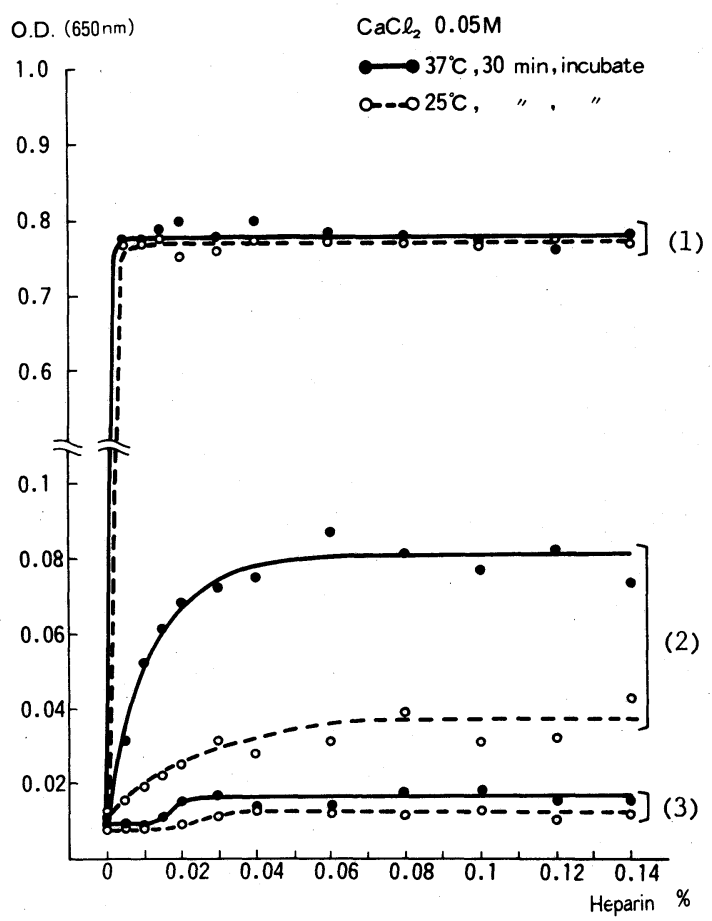

Fig. 3. Dependence of precipitate formation upon heparin concentration temperature, and $\mathrm{NaCl}$ concentration at $25^{\circ} \mathrm{C}(\mathrm{O})$ and $37^{\circ} \mathrm{C}(\odot) . \mathrm{CaCl}_{2}$ concentration and reaction time were fixed at $0.05 \mathrm{M}$ and $30 \mathrm{~min}$. $\mathrm{NaCl}$ concentration of (1) $0 \%,(2)$ $0.6 \%$, and (3) $0.9 \%$ correspond to solutions C, B, and A, respectively.

$0.05 \mathrm{M} \mathrm{CaCl}_{2}, 0.1 \%$ heparin, and a reaction temperature of $37^{\circ} \mathrm{C}$ for $30 \mathrm{~min}$.

\section{Confirmation of precipitate composition by electrophoresis}

To confirm that the respective precipitates consisted of the specified types of lipoproteins, the lipoproteins in each membrane filtrate were examined by agarose gel electrophoresis, after concentration of the filtrates using a collodion pack. VLDL, LDL, and HDL were detected in the filtrate after precipitation with solution $\mathrm{A}$, while there was no chylomicron fraction, indicating that the precipitate adherent to the membrane contained only chylomicron. Only LDL and HDL were detected in the filtrate obtained with solution $\mathrm{B}$, while in the filtrate obtained with solution C, only HDL was present (Fig. 4). Thus, it was confirmed that the required lipoproteins were indeed precipitated with the respective $\mathrm{NaCl}$ solutions and adhered quantitatively on the membrane filtrate. Also, none of the filtrates displayed any nephelometrical turbidity, indicating that the precipitates were completely removed from the filtrates and adhered onto the membranes. 


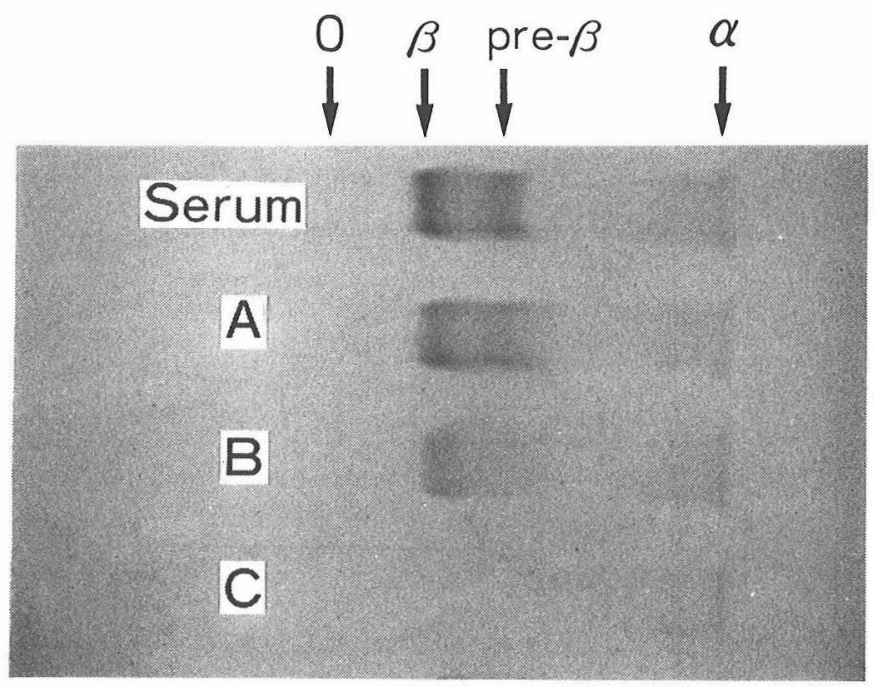

Fig. 4. Agarose gel electrophoresis of filtrates after precipitating with solution A, B, and C. Arrows of $\alpha, \beta$, and pre- $\beta$ represent alpha-, beta-, and prebeta-lipoprotein bands, respectively.

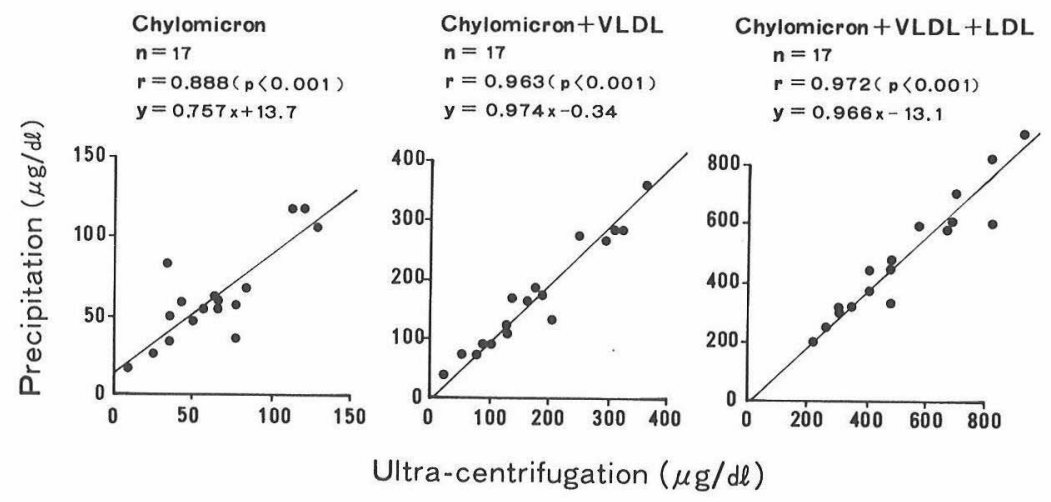

Fig. 5. Correlation between tocopherol values in individual lipoprotein fractions determined by precipitation and ultracentrifugation methods.

\section{Intra-assay reproducibility}

Two kinds of serum samples were assayed ten times; the means of CV (coefficient of variation) value were $10.8,9.8$, and $8.6 \%$ for solutions, $\mathrm{A} \mathrm{B}$, and $\mathrm{C}$, respectively.

\section{Comparison with the ultracentrifugation technique}

Tocopherol values in individual lipoprotein fractions obtained by the ultracentrifugation technique were compared with those determined by the precipitation 
Table 1. Comparison of tocopherol content in individual lipoprotein fractions determined by precipitation and ultracentrifugation methods. Samples were obtained from 17 healthy adults.

\begin{tabular}{lcc}
\hline & $\begin{array}{c}\text { Precipitation } \\
(\mu \mathrm{g} / 100 \mathrm{ml})\end{array}$ & $\begin{array}{c}\text { Ultracentrifugation } \\
(\mu \mathrm{g} / 100 \mathrm{ml})\end{array}$ \\
\hline Chylomicron tocopherol & $66.4 \pm 35.4$ & $69.5 \pm 41.5$ \\
VLDL tocopherol & $136.2 \pm 171.9$ & $138.9 \pm 167.6$ \\
LDL tocopherol & $327.1 \pm 146.2$ & $353.8 \pm 142.8$ \\
HDL tocopherol & $428.1 \pm 212.8$ & $395.6 \pm 181.9$ \\
Tocopherol ratio of VLDL/LDL & $0.43 \pm 0.56$ & $0.42 \pm 0.55$ \\
Tocopherol ratio of LDL/HDL & $0.79 \pm 0.32$ & $0.88 \pm 0.22$ \\
\hline
\end{tabular}

Mean \pm SD.

methods. The subjects were 17 healthy adult male and female volunteers. Figure 5 shows a close correlation between the tocopherol values in lipoprotein fractions obtained by the two methods. Table 1 also shows the tocopherol content of individual lipoprotein fractions determined by both methods. The values obtained by the precipitation method were generally consistent with those obtained by ultracentrifugation. However, LDL tocopherol content obtained by precipitation was slightly lower than that obtained by the centrifugation, while, conversely, HDL tocopherol displayed higher values when assayed by precipitation. Since the differences between the two techniques were very small, the precipitation method appears to be suitable for determination of lipoprotein tocopherol in mass clinical examinations by virtue of its simplicity and convenience.

\section{REFERENCES}

1) Hatch, F. T., and Lees, R. S. (1968): Practical methods for plasma lipoprotein analysis. Adv. Lipid Res., 6, 1-68.

2) Baker, H., Frank, O., Feingold, S., and Leevy, C. M. (1967): Vitamin distribution in human plasma proteins. Nature, 215, 84-85.

3) McCormick, E. C., Cornwell, D. G., and Brown, J. B. (1960): Studies on the distribution of tocopherol in human serum lipoproteins. J. Lipid Res., 1, 221-228.

4) Lambert, D., and Mourot, J. (1984): Vitamin E and lipoproteins in hyperlipoproteinemia. Atherosclerosis, 53, 327-330.

5) Takahashi, Y., Uruno, K., and Kimura, S. (1977): Vitamin E binding proteins in human serum. J. Nutr. Sci. Vitaminol., 23, 201-209.

6) Behrens, W. A., Thompson, J. N., and Madere, R. (1982): Distribution of alphatocopherol in human plasma lipoproteins. Am. J. Clin. Nutr., 35, 691-696.

7) Behrens, W. A., and Madere, R. (1986): Alpha- and gamma-tocopherol in human serum. Am. J. Coll. Nutr., 5, 91-96.

8) Burstein, M., Scholnick, H. R., and Morfin, R. (1970): Rapid method for the isolation 
of lipoproteins from human serum by precipitation with polyanions. J. Lipid Res., 11, 583-595.

9) Sawada, S., Ikekita, E., Hirao, H., Sudo, H., Yamaura, T., and Yamamoto, A. (1979): Enzymatic analysis of high-density lipoprotein cholesterol prepared by heparin-Ca precipitation method. Rinshou Byori (in Japanese), 27, 528-532.

10) Sasaki, T., Tanemura, K., and Kubota, N. (1977): Evaluation of the serum lipoprotein fraction values estimated by the turbidimetric method. Rinshou Byori (in Japanese), 25, 931-934.

11) Mino, M., Kitagawa, M., and Nakagawa, S. (1985): Red blood cell tocopherol concentrations in a normal population of Japanese children and premature infants in relation to the assessment of vitamin E status. Am. J. Clin. Nutr., 41, 631-638. 